\title{
Managing in Tough Times: Downsized- Maintaining Your Access to Health Care ${ }^{1}$
}

Michael S. Gutter and Selena Garrison ${ }^{2}$

In addition to managing one's cash flows during tough times, it is also important to protect access to essential services; one critical service is health care. If you lose your job and your employer had health insurance available to you, it is important to understand your rights and responsibilities with respect to maintaining your health care coverage.

\section{Your Rights}

The ability to maintain your health care coverage is protected by the Consolidated Omnibus Budget Reconciliation Act of 1985 (COBRA). In addition, you cannot be discriminated against coverage based on preexisting conditions as a result of the Health Insurance Portability and Accountability Act (HIPAA) of 1996.

\section{What does COBRA provide for?}

COBRA provides for continued participation in your employer-provided health care plan for 18 months after your employment ends. If you qualify for Social Security Disability payments, you may be able to extend your coverage an additional 11 months. This time allows you to look for another job and secure a longer term plan for health care expenses, ideally by participating in a new employer's plan.

Keep in mind that COBRA does not require your former employer to continue paying its portion of your health insurance premium. This means that while you are entitled to continue using the plan, you would be responsible for $100 \%$ of the cost. This can be expensive and families need to plan ahead for this increase in health care insurance premium cost.

\section{What does HIPPA protect?}

One of the major concerns for those with existing health issues is the pre-existing conditions clause on many insurance plans. This provision withholds coverage for a certain amount of time for medical conditions a participant had prior to enrolling in the plan. In most instances, HIPAA requires a 12-month maximum limit on exclusions for pre-existing conditions. In fact new plans are only able to look back for pre-existing conditions for up to 6 months. This limit is increased to 18 months for late enrollees or those enrolling after their special enrollment periods. In addition, if you had "creditable coverage" from your previous employer, your new employer's plan is required to reduce this twelve month exclusion by the number of days you previously had credit. Your previous employer is required to

1. This document is FCS7238, one in a series of the Department of Family, Youth and Community Sciences, Florida Cooperative Extension Service, Institute of Food and Agricultural Sciences, University of Florida. Publication date: October 2009. Please visit the EDIS Web site at http://edis.ifas.ufl.edu.

2. Michael S. Gutter, assistant professor and family financial management specialist; Selena Garrison, graduate student; Department of Family, Youth and Community Sciences, Institute of Food and Agricultural Sciences; University of Florida; Gainesville 32611. 
provide documentation of your previous coverage. This creditable coverage certificate will verify your enrollment period(s) in previous plans; a current employer can provide this document prior to termination. You should also be able to obtain this document after termination. Thus, if you have a twelve month exclusion on a new plan, but had 6 months creditable coverage, your exclusion should be reduced by the 6 months you had creditable coverage. However, this rule may not apply if you had a major break in coverage on your previous plan.

If group coverage is not available, and if you have completely exhausted COBRA and other continuation coverage, you always have the right to seek individual coverage. HIPAA also provides you the right to enroll under your spouse's plan during a special enrollment period.

\section{Paying for the Coverage}

Figuring out how to pay for health care coverage can be stressful, especially if you were not planning for such an expense. It is important to know the strategies and options available to help you maintain health care coverage from a financial aspect.

\section{Budget}

One of the most important aspects of planning to pay for health care coverage (and for all financial planning, in general) is to create a budget. By establishing a plan for earning, saving, and spending money, you will be more likely to be able to meet your needs, including health care coverage.

To create a budget, take the following steps:

1. Estimate the monthly take-home pay for you and anyone else in your household who contributes income to family expenses.

2. Estimate and write down your basic expenses, including those expenses that occur quarterly or semi-annually, such as your insurance. To determine how much you spend, look at bank records, credit card bills, checkbook logs, etc. If you are unable to recall the amounts, keep records of expenditures for two or three months.

3. Test your budget. For a month, keep a logged record of all the money you spend. This trial test will show whether the plan is realistic. Look carefully at your expenditures and try to locate "money leaks," or spending that you never really intended.

Remember that sticking to a budget will take work. If you want to reach your goal of maintaining health care coverage, you may have to reduce spending in other areas.

Examples of ways to reduce spending include limiting eating out, limiting excessive driving, limiting the purchase of tobacco products and alcohol, and limiting credit card use to emergencies only.

\section{Health Savings Accounts}

On December 8, 2003, President Bush signed a Medical bill that created Health Savings Accounts (HSAs). These tax-free accounts allow individuals to save for future qualified medical and retiree health expenses. If you have an HSA, you may be allowed to use those funds to pay for health care coverage in the event of a job loss. Thus, while your health care expense would go up, it would be offset by the deductibility of funds allocated to the HSA. Note that an HSA is not appropriate for everyone. In particular, an HSA may be less attractive if you have pre-existing conditions, which make it challenging to switch plans that work well with HSAs. Also, if your expenses 
would exceed a couple thousand dollars per year, this is likely not the best choice. Those most likely to save the most money and be approved for coverage are young, selfemployed, and healthy, with historically few medical expenses.

\section{Personal Savings}

Another option is to utilize personal savings and emergency funds to pay for health care coverage. Also, you can withdraw funds from Individual Retirement Accounts (IRAs) without penalty to pay health insurance premiums in the event of job loss. Using your IRA to pay for health care coverage, however, is a last resort since it places your financial future at risk.

IN SUMMARY, losing one's job status and benefits eligibility is a shock to any family's budget. Health care expenses are often costly without plan coverage, which may inhibit families from receiving the care they need; this typically only leads to larger problems in time. One reason is that not everyone knows their rights when it comes to health care coverage. Many individuals, especially those with medical conditions, or even with young children, need to maintain healthcare coverage to take care themselves and their dependents. While HIPAA and COBRA provide several safeguards so families have choices for health care coverage when losing the plan they already have, those choices can still be very costly. However, as with any and all expenses, reviewing our spending plans periodically to know how any change to income or cost of coverage could be managed is a protective measure that we can all afford."

\section{REFERENCES}

Pollitz, K.; Libster, J.; Kofman, M.; Bangit, E.; \& Lucia, K. (2007). A consumer's guide to getting and keeping health insurance in Florida. [Online]. http://healthinsuranceinfo.net/statecoverageguides/FloridaHealthInsuranceGuide.pdf

Turner, J., Gutter, M.S., \& Torres, N.I. (2009). Cutting costs to live within your income. [Online]. http://edis.ifas.ufl.edu/HE153

U.S. Department of Labor. (n.d.). Protecting retirement and health benefits after job loss. [Online]. http://www.dol.gov/ebsa/publications/protecting_benefits.html

U.S. Department of Labor. (n.d.). Work changes require health choices: Protect your rights. [Online]. http://www.dol.gov/ebsa/publications/work_changes.html

U.S. Department of the Treasury. (n.d.). Health savings accounts. [Online]. http://www.ustreas.gov/offices/public-affairs/hsa/ 